\title{
CARBOIDRATOS SOLÚVEIS, DIGESTIBILIDADE "IN VITRO" DA MATÉRIA SECA E ÁCIDOS ORGÂNICOS DAS SILAGENS DE TRÊS GENÓTIPOS DE MILHETO [Pennisetum glaucum (L). R. Br.] EM DIFERENTES PERIODOS DE FERMENTAÇÃO
}

\author{
ROBERTO GUIMARÃES JÚNIOR ${ }^{1}$, LÚCIO CARLOS GONÇALVES ${ }^{2}$, JOSÉ AVELINO SANTOS \\ RODRIGUES ${ }^{3}$, NORBERTO MÁRIO RODRIGUEZ ${ }^{2}$, ANA LUIZA COSTA CRUZ BORGES ${ }^{2}$, IRAN \\ BORGES $^{2}$, ELOÍSA OLIVEIRA SIMÕES SALIBA², DIOGO GONZAGA JAYME ${ }^{4}$, DANIEL ANANIAS \\ DE ASSIS PIRES ${ }^{4}$
}

\begin{abstract}
${ }^{1}$ Médico Veterinário, Doutorando em Ciência Animal, Escola de Veterinária da Universidade Federal de Minas Gerais - EV-UFMG. Av. Antônio Carlos 6627, Pampulha, CEP. 30123-970 Belo Horizonte, MG. E-mail: robertogjunior@hotmail.com

${ }^{2}$ Professor do Departamento de Zootecnia da Escola de Veterinária da Universidade Federal de Minas Gerais - UFMG. Av. Antônio Carlos 6627, Pampulha, CEP. 30123-970 Belo Horizonte, MG.

${ }^{3}$ Pesquisador da EMBRAPA Milho e Sorgo. Caixa postal 151, CEP. 35701-970 Sete Lagoas, MG.

${ }^{4}$ Médico Veterinário, Doutorando em Ciência Animal, Escola de Veterinária da Universidade Federal de Minas Gerais - EV-UFMG. Av. Antônio Carlos 6627, Pampulha, CEP. 30123-970 Belo Horizonte, MG.
\end{abstract}

Revista Brasileira de Milho e Sorgo, v.4, n.1, p.95-103, 2005

RESUMO - Foram determinados os valores de carboidratos solúveis, digestibilidade in vitro da matéria seca e ácidos orgânicos (lático, acético e butírico) das silagens de três genótipos de milheto (CMS-1, BRS-1501 e BN-2) com um, três, cinco, sete, 14, 28 e 56 dias de fermentação. Uma grande variação nos teores de carboidratos solúveis foi observada para o material original dos três genótipos avaliados, sendo que o BN-2 se destacou entre os demais apresentando valor de $8,33 \%$. Houve um grande consumo desta fração com o avançar do processo fermentativo e a partir do dia 5 os genótipos mostraram-se semelhantes estatisticamente. Após 56 dias de fermentação os valores médios para ácido lático, acético e butírico foram de 6,72\%,1\% e $0,02 \%$, respectivamente. A digestibilidade in vitro da matéria seca não foi influenciada pelo processo fermentativo e seus valores variaram de 52,93 a 57,18\% nos materiais originais e de 51,78 a 55,36\% nas silagens após 56 dias de fermentação. De acordo com os parâmetros avaliados, os três genótipos de milheto podem ser indicadas como opção para produção de silagem na época da safrinha.

Palavras-chave: nutrição animal, valor nutricional, ruminantes, silagem, milheto.

\section{SOLUBLE CARBOHYDRATES, “IN VITRO” DRY MATTER DIGESTIBILITY AND ORGANIC ACIDS OF THREE PEARL MILLET GENOTYPES SILAGES [Pennisetum glaucum (L). R. Br.] IN DIFFERENT FERMENTATION PERIODS}

\begin{abstract}
This paper determined the soluble carbohydrates, the "in vitro" dry matter digestibility (IVDMD) and the organic acids of three pearl millet genotypes silage, after $1,3,5,7,14,28$ and 56 days ensiling in PVC laboratory silos. A great difference was found among soluble carbohydrate contents in green forages and $\mathrm{BN}-2$ genotype presented
\end{abstract}


the higher value $(8.33 \%)$. There was a high utilization of this fraction throughout the fermentation process, and after the fifth day the three pearl millet genotypes silage showed similar values $(\mathrm{P}>0.05)$. After 56 days ensiling, the latic, acetic and butiric acids mean values were $6.72 \%, 1 \%$ and $0.02 \%$, respectively. The in vitro dry matter digestibility was not modified throughout the fermentation process. The IVDMD ranged from 52.93 to $57.18 \%$ in green forage and from 51.78 to $55.36 \%$ in silage in the last evaluation period (day 56 ). According to the evaluated parameters, the three pearl millet genotypes can be suggested for silage making.

Key Words: animal nutrition, nutritional value, ruminants, silage, pearl millet.

Adequar as exigências nutricionais dos animais à oferta de forragem verde de boa qualidade ao longo do ano tem sido um desafio constante e uma meta a ser atingida pelos nutricionistas. No Brasil, a produção de pastagem se concentra no período do verão, onde, em situações normais, a oferta de forragem verde é abundante e, utilizando-se um sistema adequado de manejo, pode-se oferecer volumoso de boa qualidade para os animais. Mas durante o inverno, a reduzida capacidade de suporte das pastagens e sua baixa qualidade limitam e impedem uma adequada produção animal (Costa, 1997). Sendo assim, o uso da silagem torna-se uma opção para se contornar o problema de flutuação estacional da produção de pastagens e conseqüentemente diminuição da produção animal no período do inverno.

O milheto é um cereal de grande importância mundial, sendo considerado uma excelente alternativa para produção de grãos e forragem (Café et al., 2002). No Brasil, a área plantada total gira em torno de 2,1 milhões de hectares, onde a cultura destina-se à produção de palhada para plantio direto, produção de forragem para pastejo, implantação e recuperação de pastagens e para produção de silagem e grãos. É uma planta muito apreciada pelo gado, nutritiva e não possui fatores antinutricionais como os cianogênicos (Costa, 1992; Lima et al., 1999). Apesar de ser uma gramínea de verão, apresenta acentuada tolerância à seca, podendo ser cultivada em regiões onde o índice pluviométrico não ultrapassa os $400 \mathrm{~mm}$ anuais (Bonamigo et al., 1999), sendo considerada uma cultura de grande potencial para plantios em sucessão ou safrinha (Pereira et al., 1993).

No entanto, são poucos os estudos sobre a composição química do material original e perfil de fermentação da silagem de milheto. O objetivo deste trabalho foi determinar os valores de carboidratos solúveis (CHO), digestibilidade "in vitro" da matéria seca (DIVMS) e ácidos orgânicos (lático, acético e butírico) das silagens de três genótipos de milheto em diferentes períodos de fermentação.

\section{Material e Métodos}

Os genótipos de milheto (variedades CMS-1, BRS-1501 e BN-2) foram plantados, colhidos e ensilados nas dependências da EMBRAPA Milho e Sorgo, localizada a $19^{\circ} 28^{\prime}$ de latitude sul, $44^{\circ} 15^{\prime}$ de longitude oeste de Greenwich, a uma altitude de 732 metros, no município de Sete Lagoas, Minas Gerais.

Os materiais foram cultivados em canteiros experimentais de 5,0 $\mathrm{m} \mathrm{x} \mathrm{4,5} \mathrm{m,} \mathrm{utilizan-}$ do-se quatro linhas por tratamento, com espaçamento de $0,90 \mathrm{~m}$ e cinco metros de comprimento, totalizando uma área útil de $18 \mathrm{~m}^{2}$. Cada genótipo foi plantado em quatro canteiros, que constituíram as suas repetições. A adubação 
de plantio foi equivalente a $350 \mathrm{~kg} \mathrm{ha}^{-1}$ de 8-2816 (NPK) e a de cobertura a $100 \mathrm{~kg} \mathrm{ha}^{-1}$ de uréia, de acordo com a análise de solo e necessidade da cultura. A semeadura foi realizada no mês de março de 1998 e a colheita após 82 dias, com os grãos em estádio leitoso. Em seguida, os materiais foram picados em picadeira estacionária (Nogueira, Modelo DPM-4) em partículas de tamanho médio de $2 \mathrm{~cm}$, homogeneizados manualmente e imediatamente ensilados em silos de laboratório dotados de tampas com válvulas tipo Bünsen. Nestes, os materiais foram compactados com auxílio de um soquete de madeira, de modo a se conseguir uma densidade entre 500 a $600 \mathrm{~kg}$ $\mathrm{m}^{-3}$. Uma subamostra do material picado foi retirada para ser posteriormente analisada como material original.

A abertura dos silos foi realizada com um, três, cinco, sete, 14, 28 e 56 dias após a ensilagem. A silagem foi removida dos silos e colocada em recipiente plástico, previamente limpo e seco, para homogeneização. Parte do material original e da silagem foi pesado e levado à estufa de ventilação forçada, por 72 horas, para determinação da matéria pré-seca a $65^{\circ} \mathrm{C}(\mathrm{AOAC}, 1980)$. Após determinação da matéria pré-seca, os materiais foram moídos em moinho tipo Willey dotados de peneira de $1 \mathrm{~mm}$ e acondicionados em frascos de polietileno dotados de tampa. Nas amostras pré-secas dos materiais originais e das silagens foram determinados os teores de carboidratos solúveis (CHOs) (Bailey, 1967, modificado por Valadares Filho, 1981) e digestibilidade "in vitro" da matéria seca (DIVMS) (Tilley \& Terry, 1963).

No suco da silagem, extraído com o auxílio de uma prensa hidráulica, foram imediatamente determinados os valores de $\mathrm{pH}$ em potenciômetro de Beckman Expandomatic SS2 e teor de nitrogênio amoniacal por destilação com óxido de magnésio e cloreto de cálcio, empregando-se solução receptora de ácido bórico e titulação com solução de ácido clorídrico 0,1 N. Para determinação dos teores de ácidos orgânicos das silagens as amostras diluídas em ácido metafosfórico foram descongeladas e centrifugadas duas vezes por 15 minutos a 5000 rpm antes de serem filtradas em filtro de náilon com poros de $0,45 \mu \mathrm{m}$. Em seqüência, este material foi utilizado para a determinação dos valores dos ácidos lático, acético e butírico por cromatografia gasosa no aparelho Shimadzu-GC - 17A, utilizando coluna - Nukol FFAP de 15m por $0,52 \mathrm{~mm}$, DF $0,5 \mu \mathrm{m}$.

Para análise das variáveis DIVMS e CHOs utilizou-se um delineamento experimental inteiramente ao acaso, adotando-se um esquema fatorial 3 x 8 (genótipos x materiais originais + dias de abertura). Para a avaliação dos ácidos orgânicos das silagens o delineamento experimental foi o mesmo, porém num esquema fatorial $3 \times 6$. Os dados foram submetidos à análise de variância, adotando-se o software " SAEG" versão 7.0, 1997. As médias foram comparadas pelo teste de "Student Newman Kells" (SNK) a 5\% de probabilidade.

\section{Resultados e Discussão}

Os valores de carboidratos solúveis (Tabela 1) variaram de $8,33 \%$ para a variedade $\mathrm{BN}$ 2 no material original até $0,38 \%$ para a variedade BRS-1501 no dia 56. Uma diferença significativa foi observada entre os materiais com relação à concentração de carboidratos solúveis no material original. A variedade $\mathrm{BN}-2$ apresentou o maior valor $(8,33 \%)$, sendo seguido por CMS$1(5,75 \%)$ e por BRS-1501 (2,59\%). Machado Filho e Mühlbach (1986) encontraram valor de $14,91 \%$ para a planta do milheto quando colhida em estádio de grão leitoso. Já Chaves (1997) obteve $8,56 \%$ no material original, valor similar ao 
TABELA 1. Carboidratos solúveis em álcool (\% da matéria seca) no material original (MO) e nas silagens de três genótipos de milheto, em diferentes períodos de fermentação.

\begin{tabular}{|c|c|c|c|c|c|c|c|c|}
\hline \multirow{2}{*}{ Genótipo } & \multirow{2}{*}{ MO } & \multicolumn{7}{|c|}{ Dia de abertura } \\
\hline & & 1 & 3 & 5 & 7 & 14 & 28 & 56 \\
\hline CMS-1 & $5,75^{\mathrm{Ab}}$ & $6,93^{\text {Aa }}$ & $2,89^{\mathrm{Ba}}$ & $1,03^{\mathrm{BCa}}$ & $0,62^{\mathrm{Ca}}$ & $0,54^{\mathrm{Ca}}$ & $1,23^{\mathrm{Ca}}$ & $0,53^{\mathrm{Ca}}$ \\
\hline BRS-1501 & $2,59^{\mathrm{Ac}}$ & $2,14^{\mathrm{Ab}}$ & $0,83^{\mathrm{Ab}}$ & $0,69^{\mathrm{Aa}}$ & $0,55^{\mathrm{Aa}}$ & $0,54^{\mathrm{Aa}}$ & $0,47^{\mathrm{Aa}}$ & $0,38^{\mathrm{Aa}}$ \\
\hline $\mathrm{BN}-2$ & $8,33^{\text {Aa }}$ & $7,76^{\mathrm{Aa}}$ & $3,63^{\mathrm{Ba}}$ & $2,28^{\mathrm{BCa}}$ & $1,67^{\mathrm{Ca}}$ & $1,01^{\mathrm{Ca}}$ & $0,73^{\mathrm{Ca}}$ & $0,64^{\mathrm{Ca}}$ \\
\hline Média & $5,56^{\mathrm{A}}$ & $5,61^{\mathrm{A}}$ & $2,45^{\mathrm{B}}$ & $1,33^{\mathrm{C}}$ & $0,95^{\mathrm{C}}$ & $0,81^{\mathrm{C}}$ & $0,70^{\mathrm{C}}$ & $0,52^{\mathrm{C}}$ \\
\hline
\end{tabular}

Médias seguidas por letras maiúsculas iguais na mesma linha não diferem estatisticamente. Médias seguidas por letras minúsculas iguais na mesma coluna não diferem estatisticamente. Teste $\mathrm{SNK}, \mathrm{p}<0,05, \mathrm{CV}=49,90 \%$.

verificado no material original de $\mathrm{BN}-2$. O valor médio de $5,56 \%$ de carboidratos solúveis encontrado para o material original do milheto é superior ao relatado por Pereira (2003) para cultura do girassol $(3,2 \%)$ e inferior aos citados por Antunes (2001) e Rocha Júnior (1999) para as culturas de milho $(7,17 \%)$ e sorgo $(8,35 \%)$, respectivamente.

Avaliando-se o comportamento dos genótipos ao longo do processo fermentativo pôde-se observar grande consumo de carboidratos para todos os materiais. As maiores reduções nas concentrações de carboidratos solúveis foram verificadas entre os dias 1 e 3 , não sendo observadas diferenças significativas entre os materiais originais e as silagens obtidas após um dia de fermentação (dia 1 de abertura). Em função dos baixos valores iniciais obtidos para o BRS-1501 e o elevado coeficiente de variação desta análise, não foi observado, para este genótipo, diferenças estatísticas entre material original e as silagens ao longo do processo fermentativo. CMS-1 e BN2 estabilizaram as suas concentrações de carboidratos entre o quinto e o sétimo dia. Quando avaliado numa mesma época de abertura o BRS-1501 mostrou valores de carboidratos solúveis inferiores aos demais até o dia 3 , sendo que a partir desse ponto os três genótipos foram semelhantes $(\mathrm{p}>0,05)$.

O efeito do tempo de fermentação sobre os teores de carboidratos solúveis (CHOs) das silagens foi cúbico, conforme demonstrado pelas seguintes equações de regressão:

$\mathrm{CHO}(\%) \mathrm{CMS}-1=6,5414-1,0882 \mathrm{X}+0,0476 \mathrm{X}^{2}$ $-0,0005 \mathrm{X}^{3}\left(\mathrm{r}^{2}=0,70\right)$

CHO (\%) BRS-1501 = 1,8924 - 0,2430X + $0,0101 \mathrm{X}^{2}-0,0001 \mathrm{X}^{3}\left(\mathrm{r}^{2}=0,52\right)$

$\mathrm{CHO}(\%) \mathrm{BN}-2=7,3577-1,0283 \mathrm{X}+0,0411 \mathrm{X}^{2}$ $-0,004 X^{3}\left(r^{2}=0,68\right)$

Os valores de digestibilidade in vitro da matéria seca (DIVMS) no material original e nas silagens podem ser verificados na Tabela 2. Os valores variaram de $51,30 \%$ para $\mathrm{BN}-2$, no dia 1 (um) de abertura, até 57,81\% para BRS-1501 neste mesmo período. No dia 56 de abertura as variedades CMS-1 e o BRS-1501 apresentaram os maiores valores de DIVMS, 54,44 e 55,36\%, respectivamente e $\mathrm{BN}-2$ apresentou DIVMS de $51,8 \%$ neste mesmo período. A DIVMS média aos 56 dias foi de $53,86 \%$ para os três genótipos avaliados.

Os valores de DIVMS obtidos neste experimento são inferiores aos relatados por Seiffert 
\& Prates (1978) para silagens confeccionadas com os cultivares de milheto variedade Comum (59,87\%) e AO64 (55,37\%), avaliados após 30 dias de ensilagem, e para silagens de milho após 56 dias de fermentação com valor médio de 57,08\% (Antunes, 2001). Entretanto, estes valores são superiores aos obtidos por Pereira (2003), com silagens de girassol colhidas no período da safrinha, que apresentaram após 56 dias de ensilagem DIVMS média de 49,1\%, e similares às DIVMS obtidas por Rocha Júnior (1999) $(53,45 \%)$, estudando sete genótipos de sorgo.

Na comparação entre genótipos no mesmo período de abertura as variedades CMS-1 e BRS-1501 mostraram-se estatisticamente superiores, exceção feita para os dias 14 e 28 de abertura dos silos, onde todos os materiais foram semelhantes $(p>0,05)$. Em todas as variedades, a ensilagem não alterou os valores de DIVMS do material original, fato este desejável tendo em vista que a qualidade do alimento não foi alterada.

Os teores de ácido lático no suco das silagens são mostrados na Tabela 3. Observouse uma variação de $2,22 \%$ para a silagem de BRS1501 na abertura do dia 3 a 7,95\% para este mesmo genótipo na abertura do dia 56 .
Os teores de ácido lático encontrados neste experimento são superiores aos valores de 5,85 e $0,72 \%$ observados por Machado Filho \& Mühlbach (1986) e Chaves (1997), respectivamente. Andrade \& Andrade (1982), avaliando a qualidade das silagens de milheto confeccionadas com a planta em três idades de crescimento $(68,81$ e 134 dias), obtiveram valores que variaram de 2,29 a 8,89\%, após 40 dias de ensilagem.

Avaliando-se o efeito do tempo de fermentação sobre os genótipos, nota-se que para as variedades CMS-1 e BN-2 não foram observadas diferenças estatísticas ( $p>0,05)$, o mesmo não sendo observado para o BRS-1501. Quando avaliados numa mesma data de abertura os materiais mostraram-se estatisticamente semelhantes.

O ácido lático é o principal ácido orgânico responsável pela queda do $\mathrm{pH}$ durante o processo da ensilagem (McDonald et al., 1991). O valor médio geral de $6,72 \%$, obtido para as silagens no dia 56 de abertura, permitem classificá-las como silagens de muito boa qualidade (Paiva, 1976).

Os teores de ácido acético (Tabela 4.) variaram de 0,87 para a variedade BRS-1501 no dia 3 de abertura a 1,22 para o genótipo CMS-1

TABELA 2. Digestibilidade in vitro da matéria seca (\% da matéria seca) do material original (MO) e das silagens de três genótipos de milheto, em diferentes períodos de fermentação.

\begin{tabular}{lcccccccc}
\hline \multirow{2}{*}{ Genótipo } & \multirow{2}{*}{ MO } & \multicolumn{7}{c}{ Dia de Abertura } \\
\cline { 3 - 9 } & & 1 & 3 & 5 & 7 & 14 & 28 & 56 \\
\hline CMS-1 & $55,45^{\mathrm{Aab}}$ & $55,71^{\mathrm{Aa}}$ & $55,41^{\mathrm{Aa}}$ & $55,13^{\mathrm{Aa}}$ & $55,40^{\mathrm{Aa}}$ & $54,56^{\mathrm{Aa}}$ & $54,03^{\mathrm{Aa}}$ & $54,44^{\mathrm{Aa}}$ \\
BRS-1501 & $57,18^{\mathrm{Aa}}$ & $57,81^{\mathrm{Aa}}$ & $57,26^{\mathrm{Aa}}$ & $57,24^{\mathrm{Aa}}$ & $56,33^{\mathrm{Aa}}$ & $54,97^{\mathrm{Aa}}$ & $56,44^{\mathrm{Aa}}$ & $55,36^{\mathrm{Aa}}$ \\
BN-2 & $52,93^{\mathrm{Ab}}$ & $51,30^{\mathrm{Ab}}$ & $51,30^{\mathrm{Ab}}$ & $53,46^{\mathrm{Ab}}$ & $52,40^{\mathrm{Ab}}$ & $54,32^{\mathrm{Aa}}$ & $54,42^{\mathrm{Aa}}$ & $51,78^{\mathrm{Ab}}$ \\
Média & $55,19^{\mathrm{A}}$ & $54,94^{\mathrm{A}}$ & $54,65^{\mathrm{A}}$ & $55,94^{\mathrm{A}}$ & $54,71^{\mathrm{A}}$ & $54,62^{\mathrm{A}}$ & $54,96^{\mathrm{A}}$ & $53,86^{\mathrm{A}}$ \\
\hline
\end{tabular}

Médias seguidas por letras maiúsculas iguais na mesma linha não diferem estatisticamente. Médias seguidas por letras minúsculas iguais na mesma coluna não diferem estatisticamente. Teste $\mathrm{SNK}, \mathrm{p}<0,05, \mathrm{CV}=3,29 \%$. 
TABELA 3. Ácido lático (\% da matéria seca) nas silagens de três genótipos de milheto, em diferentes períodos de fermentação.

\begin{tabular}{lcccccc}
\hline \multirow{2}{*}{ Genótipo } & \multicolumn{5}{c}{ Dia de Abertura } \\
\cline { 2 - 7 } & 3 & 5 & 7 & 14 & 28 & 56 \\
\hline CMS-1 & $4,95^{\mathrm{Aa}}$ & $7,50^{\mathrm{Aa}}$ & $5,45^{\mathrm{Aa}}$ & $4,31^{\mathrm{Aa}}$ & $6,86^{\mathrm{Aa}}$ & $7,09^{\mathrm{Aa}}$ \\
BRS-1501 & $2,22^{\mathrm{Ba}}$ & $6,67^{\mathrm{Aa}}$ & $5,41^{\mathrm{ABa}}$ & $4,51^{\mathrm{ABa}}$ & $4,82^{\mathrm{ABa}}$ & $7,95^{\mathrm{Aa}}$ \\
BN-2 & $2,71^{\mathrm{Aa}}$ & $6,28^{\mathrm{Aa}}$ & $5,09^{\mathrm{Aa}}$ & $4,33^{\mathrm{Aa}}$ & $5,89^{\mathrm{Aa}}$ & $5,12^{\mathrm{Aa}}$ \\
Média & $3,29^{\mathrm{C}}$ & $6,82^{\mathrm{A}}$ & $5,32^{\mathrm{AB}}$ & $4,38^{\mathrm{BC}}$ & $5,86^{\mathrm{AB}}$ & $6,72^{\mathrm{A}}$ \\
\hline
\end{tabular}

Médias seguidas por letras maiúsculas iguais na mesma linha não diferem estatisticamente. Médias seguidas por letras minúsculas iguais na mesma coluna não diferem estatisticamente. Teste SNK, p<0,05, CV = 34,20\%.

TABELA 4. Ácido acético (\% da matéria seca) nas silagens de três genótipos de milheto, em diferentes períodos de fermentação.

\begin{tabular}{lcccccc}
\hline \multirow{2}{*}{ Genótipo } & \multicolumn{5}{c}{ Dia de Abertura } \\
\cline { 2 - 7 } & 3 & 5 & 7 & 14 & 28 & 56 \\
\hline CMS-1 & $0,88^{\mathrm{Aa}}$ & $0,94^{\mathrm{Aa}}$ & $0,89^{\mathrm{Aa}}$ & $0,93^{\mathrm{Aa}}$ & $0,92^{\mathrm{Aa}}$ & $1,22^{\mathrm{Aa}}$ \\
BRS-1501 & $0,87^{\mathrm{Aa}}$ & $0,92^{\mathrm{Aa}}$ & $0,93^{\mathrm{Aa}}$ & $0,98^{\mathrm{Aa}}$ & $1,15^{\mathrm{Aa}}$ & $0,67^{\mathrm{Ab}}$ \\
BN-2 & $0,99^{\mathrm{Aa}}$ & $1,00^{\mathrm{Aa}}$ & $0,97^{\mathrm{Aa}}$ & $0,90^{\mathrm{Aa}}$ & $1,04^{\mathrm{Aa}}$ & $1,10^{\mathrm{Aa}}$ \\
Média & $0,92^{\mathrm{A}}$ & $0,95^{\mathrm{A}}$ & $0,93^{\mathrm{A}}$ & $0,94^{\mathrm{A}}$ & $1,04^{\mathrm{A}}$ & $1,00^{\mathrm{A}}$ \\
\hline
\end{tabular}

Médias seguidas por letras maiúsculas iguais na mesma linha não diferem estatisticamente. Médias seguidas por letras minúsculas iguais na mesma coluna não diferem estatisticamente. Teste $\mathrm{SNK}, \mathrm{p}<0,05, \mathrm{CV}=29,97 \%$.

no dia 56. Para uma mesma data de abertura dos silos as variedades mostraram-se iguais estatisticamente até o dia 28. No dia 56 de abertura os genótipos CMS-1 (1,22\%) e BN-2 (1,10\%) foram estatisticamente semelhantes e diferentes do BRS-1501 (0,67\%). Estes valores foram inferiores aos observados por Andrade \& Andrade (1982), que encontraram valores variando de 13,35 a $1,83 \%$, e superiores a $0,12 \%$ relatado por Chaves (1997).

Os valores de ácido acético para todas as silagens foram sempre inferiores a $2 \%$, o que as classificaria como de muito boa qualidade, segundo critérios definidos por Nogueira (1995).

A Tabela 5 mostra os teores de ácido butírico obtido para as silagens de milheto nos diferentes períodos de avaliação. Todos os genótipos avaliados apresentaram baixas concentrações deste ácido ao longo dos dias de abertura. Os valores variaram de $0,01 \%$ para a maioria dos genótipos a $0,04 \%$ para o genótipo BRS-1501 no dia 28 . Não foram observadas diferenças estatísticas entre os genótipos num mesmo tempo de abertura e entre dias de abertura para um mesmo genótipo. 
TABELA 5. Ácido butírico (\% da matéria seca) nas silagens de três genótipos de milheto, em diferentes períodos de fermentação.

\begin{tabular}{lcccccc}
\hline \multirow{2}{*}{ Genótipo } & \multicolumn{5}{c}{ Dia de Abertura } \\
\cline { 2 - 7 } & 3 & 5 & 7 & 14 & 28 & 56 \\
\hline CMS-1 & $0,01^{\mathrm{Aa}}$ & $0,01^{\mathrm{Aa}}$ & $0,02^{\mathrm{Aa}}$ & $0,01^{\mathrm{Aa}}$ & $0,02^{\mathrm{Aa}}$ & $0,03^{\mathrm{Aa}}$ \\
BRS-1501 & $0,01^{\mathrm{Aa}}$ & $0,01^{\mathrm{Aa}}$ & $0,02^{\mathrm{Aa}}$ & $0,01^{\mathrm{Aa}}$ & $0,04^{\mathrm{Aa}}$ & $0,01^{\mathrm{Aa}}$ \\
BN-2 & $0,01^{\mathrm{Aa}}$ & $0,00^{\mathrm{Aa}}$ & $0,02^{\mathrm{Aa}}$ & $0,01^{\mathrm{Aa}}$ & $0,02^{\mathrm{Aa}}$ & $0,03^{\mathrm{Aa}}$ \\
Média & $0,01^{\mathrm{A}}$ & $0,01^{\mathrm{A}}$ & $0,02^{\mathrm{A}}$ & $0,01^{\mathrm{A}}$ & $0,03^{\mathrm{A}}$ & $0,02^{\mathrm{A}}$ \\
\hline
\end{tabular}

Médias seguidas por letras maiúsculas iguais na mesma linha não diferem estatisticamente. Médias seguidas por letras minúsculas iguais na mesma coluna não diferem estatisticamente. Teste SNK, p<0,05, CV =57,06\%.

O valor médio de $0,02 \%$ encontrado para as silagens no dia de abertura 56 pode ser considerado baixo, demonstrando o controle da atividade clostridiana ao longo do processo fermentativo. Isto é uma característica favorável na silagem, tendo em vista que os clostrídios afetam negativamente a qualidade da silagem e prejudicam o seu consumo.

Andrade \& Andrade (1982) encontraram valores de ácido butírico na silagem de milheto variando de 0,22 a 4,53\%, porém Chaves (1997) obteve valor de $0,01 \%$ para este mesmo alimento.

\section{Conclusões}

De acordo com os parâmetros estudados, as silagens dos três genótipos de milheto apresentaram um adequado padrão de fermentação.

Com relação à digestibilidade in vitro da matéria seca, o processo fermentativo não alterou o valor nutricional das silagens.

O três genótipos de milheto podem ser indicados como opção para produção de silagem na época da safrinha.

\section{Literatura Citada}

ANDRADE, J. B.; ANDRADE, P. Produção de silagem de milheto (Pennisetum americanum (L.)
K. Schum.). Boletim da Indústria Animal, Nova Odessa, v. 39, n. 1, p. 67-73, 1982.

ANTUNES, R. C. Padrão de fermentação das silagens de seis genótipos de milho (Zea mays L.). 2001. 50 f. Dissertação (Mestrado em Zootecnica) - Escola de Veterinária, Universidade Federal de Minas Gerais, Belo Horizonte.

ASSOCIATION OF OFFICIALANALYTICAL CHEMISTS (AOAC). Horwitz, W. (Ed.). Official methods of analysis of the Association of Official Analytical Chemists. 13. ed. 1980.

BAILEY, R. W. Quantitative studies of ruminant digestion. II. Loss of ingested plant cabohydrates from the reticulo rumen. New Zealand Journal of Agricultural Research, Wellington, v.10, n.1, p.15-32, 1967.

BONAMIGO, L. A. A. cultura do milheto no Brasil: implantação e desenvolvimento no cerrado. In: WORKSHOP INTERNACIONAL DE Milheto, 1999, Brasília, DF. Anais... Planaltina: Embrapa Cerrados, 1999. p. 31-65.

CAFÉ, M. B.; STRINGHINI, J. H.; FRANÇA, A. F. S. Utilização do milheto na alimentação 
animal. In: SIMPÓSIO SOBRE INGREDIENTES NA ALIMENTAÇÃO ANIMAL, 2., 2002. Uberlândia. Anais... Uberlândia: Colégio Brasileiro de Nutrição Animal, 2002. p. 5-38.

CHAVES, C. Produção e valor nutritivo das silagens de capim sudão [Sorghum sudanense (Piper) Stapf, milheto (Pennisetum americanum (L.) Leeke], teosinto (Euchlaena mexicana Schrad) e milho (Zea mays L.). 1997. 56 f. Dissertação (Mestrado em Zootecnia) Universidade Federal de Lavras, Lavras.

COSTA, J. L. Produção e conservação de forragens: forragens para o gado leiteiro. São Paulo: Tortuga; Juíz de Fora: Embrapa-CNPGL, $1997.98 \mathrm{p}$.

COSTA,N. L. Estabelecimento, formação e manejo de pastagens de milheto. Lavoura Arrozoeira, Porto Alegre, v. 45, n. 405, p. 7-72, 1992.

LIMA, M. L. M.; CASTRO, F. G. F.; TAMASSIA, L. F. M. Culturas não-convencionais - girassol e milheto. In: SIMPÓSIO SOBRE NUTRIÇÃO DE BOVINOS, 7., 1999, Piracicaba. Alimentação suplementar: anais. Piracicaba: FEALQ, 1999. p. 178-195.

MACHADO FILHO, L. C. P.; MÜHLBACH, P. R. F. Efeito do emurchecimento na qualidade da silagens de Capim - Elefante (Pennisetum purpureum Schumach.) e de Milheto (Pennisetum americanum (1.) Leeke), avaliadas quimicamente. Revista da Sociedade Brasileira de Zootecnia, Viçosa, v. 15, n. 3, p. 224-233, 1986.

McDONALD, P.; HENDERSON, A. R.; HERON, S. J. E. The Biochemistry of silage. Marlow: Chalcombe, 1991. 340 p.

NOGUEIRA, F. A. S. Qualidade das silagens de híbridos de sorgo de porte baixo com e sem tanino e de colmo seco e suculento, e seus padrões de fermentação em condições de laboratório. 1995. 78 f. Dissertação (Mestrado em Zootecnia) - Escola de Veterinária da Universidade Federal de Minas Gerais, Belo Horizonte.

PAIVA, J. A. J. Qualidade da silagem da região metalúrgica de Minas Gerais. 1976. $85 \mathrm{f}$. Dissertação (Mestrado em Zootecnia) - Escola de Veterinária, Universidade Federal de Minas Gerais, Belo Horizonte.

PEREIRA, L. G. R. Potencial forrageiro da cultura do girassol (Helianthus annuus L.) para a produção de silagem. 2003. 134 f. Dissertação (Doutorado em Ciência Animal) - Escola de Veterinária, Universidade Federal de Minas Gerais, Belo Horizonte.

PEREIRA, O. G.; OBEID, J. A.; GOMIDE, J. A.; QUEIROZ, A. C.; FILHO, S. C. V. Produtividade e valor nutritivo de aveia (Avena sativa), milheto (Pennisetum americanum) e de um híbrido de Sorghum bicolor X S. sudanense. Revista da Sociedade Brasileira de Zootecnia, Viçosa, v. 22, n. 1, p. 22-30, 1993.

ROCHA JÚNIOR, V. R. Qualidade das silagens de sete genótipos de sorgo (Sorghum bicolor L. Moench) e seus padrões de fermentação. 1999. 132 f. Dissertação (Mestrado em Zootecnia) - Escola de Veterinária, Universidade Federal de Minas Gerais, Belo Horizonte.

SEIFFERT, N. F.; PRATES, E. R. Forrageiras para a ensilagem. II - Valor Nutritivo e Qualidade de Silagem de Cultivares de Milho (Zea mays, L.), sorgos (Sorghum sp.) e Milhetos (Pennisetum americanum, Schum). Revista da Sociedade Brasileira de Zootecnia, Viçosa, v. 7, n. 2, p. 183-195, 1978. 
TILLEY, J. M. A.; TERRY, R. A. A two-stage technique for the "in vitro" digestion of forage crops. Journal of British Grassland Society, Oxford, v. 18, n. 2, p. 104-111, 1963.

VALADARES FILHO, S. C. Digestibilidades aparentes e locais da digestão da matéria seca, energia e carboidratos de fenos de soja perene. 1981. 88 f. Dissertação (Mestrado em Zootecnia) - Escola de Veterinária, Universidade Federal de Minas Gerais, Belo Horizonte. 